\title{
Twenty-first-century climate change impacts on marine animal biomass and ecosystem structure across ocean basins
} Bryndum-Buchholz Andrea ${ }^{1,}{ }^{*}$, Tittensor Derek P. ${ }^{1,2}$, Blanchard Julia L. ${ }^{3}$, Cheung William W. L. ${ }^{4}$,
Coll Marta ${ }^{5,6}$, Galbraith Eric D. ${ }^{7,8}$, Jennings Simon ${ }^{9,10,11}$, Maury Olivier ${ }^{12,13}$, Lotze Heike K. ${ }^{1}$

${ }^{1}$ Dalhousie Univ, Dept Biol, Halifax, NS, Canada.

2 United Nations Environm Programme World Conserva, Cambridge, England.

3 Univ Tasmania, Ctr Marine Socioecol, Inst Marine \& Antarctic Studies, Hobart, Tas, Australia.

4 Univ British Columbia, Inst Oceans \& Fisheries, Nippon Fdn UBC Nereus Program \& Changing Ocean Re, Vancouver, BC, Canada.

${ }^{5}$ CSIC, ICM, Barcelona, Spain.

${ }^{6}$ Ecopath Int Initiat, Barcelona, Spain.

7 ICREA, Barcelona, Spain.

8 Univ Autonoma Barcelona, Inst Ciencia \& Tecnol Ambientals ICTA, Dept Math, Barcelona, Spain.

${ }^{9}$ CEFAS, Lowestoft Lab, Lowestoft, Suffolk, England.

10 Univ East Anglia, Sch Environm Sci, Norwich, Norfolk, England.

11 Int Council Explorat Sea, Copenhagen V, Denmark.

12 IRD, UMR 248 MARBEC, Paris, France.

13 Univ Cape Town, Int Lab, ICEMASA, Rondebosch, South Africa.

*Corresponding author : Andrea Bryndum-Buchholz, email address : andrea.buchholz@dal.ca

\begin{abstract}
:
Climate change effects on marine ecosystems include impacts on primary production, ocean temperature, species distributions, and abundance at local to global scales. These changes will significantly alter marine ecosystem structure and function with associated socio-economic impacts on ecosystem services, marine fisheries, and fishery-dependent societies. Yet how these changes may play out among ocean basins over the 21st century remains unclear, with most projections coming from single ecosystem models that do not adequately capture the range of model uncertainty. We address this by using six marine ecosystem models within the Fisheries and Marine Ecosystem Model Intercomparison Project (Fish-MIP) to analyze responses of marine animal biomass in all major ocean basins to contrasting climate change scenarios. Under a high emissions scenario (RCP8.5), total marine animal biomass declined by an ensemble mean of $15 \%-30 \%(+/-12 \%-17 \%)$ in the North and South Atlantic and Pacific, and the Indian Ocean by 2100, whereas polar ocean basins experienced a 20\%-80\% (+/- 35\%-200\%) increase. Uncertainty and model disagreement were greatest in the Arctic and smallest in the South Pacific Ocean. Projected changes were reduced under a low (RCP2.6) emissions scenario. Under RCP2.6 and RCP8.5, biomass projections were highly correlated with changes in net primary production and negatively correlated with projected sea surface temperature increases across all ocean basins except the polar
\end{abstract}


oceans. Ecosystem structure was projected to shift as animal biomass concentrated in different sizeclasses across ocean basins and emissions scenarios. We highlight that climate change mitigation measures could moderate the impacts on marine animal biomass by reducing biomass declines in the Pacific, Atlantic, and Indian Ocean basins. The range of individual model projections emphasizes the importance of using an ensemble approach in assessing uncertainty of future change.

Keywords : climate change, ensemble modeling, future projection, marine animal biomass, marine ecosystem models, model intercomparison, ocean basins, uncertainty 
Major biological changes in the structure and functioning of marine ecosystems have been associated with changing climates both in the past (e.g. Harnik et al., 2012; Yasuhara \& Danovaro, 2016) and in future projections (e.g. Cheung et al., 2009; Worm \& Lotze, 2016; Pecl et al., 2017). These include changes in ocean productivity (Boyce, Lewis, \& Worm, 2010; Moore et al. 2018) and species distribution and abundance (Perry et al., 2005; Cheung et al., 2009; Pinsky, Worm, Fogarty, Sarmiento, \& Levin, 2013; Lefort et al., 2015) at local to global scales. Over the coming century, these changes will have significant consequences for marine ecosystem structure and functioning as well as for ecosystem goods and services, such as the provisioning of food from fisheries and aquaculture, the production of oxygen, and storage of anthropogenic carbon (Vichi et al. 2011, Pörtner et al. 2014). Several studies have projected future changes in marine animals at the scale of Large Marine Ecosystems (LMEs; Blanchard et al., 2012), coastal seas (Barange et al., 2014) and the global ocean (Cheung et al., 2010; Blanchard et al., 2017; Galbraith, Carozza, \& Bianchi, 2017; Lotze et al., in review), yet how the ecological changes may play out in different ocean basins have not been comprehensively explored.

This article is protected by copyright. All rights reserved. 
With climate change affecting oceanographic and biological dynamics at multiple temporal and spatial scales, rates of change in marine ecosystem structure and functioning are expected to differ between ocean basins (Fossheim et al., 2015). For instance, marine organisms respond to increasing ocean temperatures through distributional shifts, with expected regional shifts toward colder deeper, further offshore or polar waters (Cheung et al., 2009; Pinsky et al., 2013), as well as global range expansions towards higher latitudes, and range retractions at equatorial boundaries (Cheung et al., 2009; Cheung et al., 2013; Fossheim et al., 2015). Furthermore, regional surface temperatures in polar marine ecosystems are increasing twice as fast as the global average, leading to a borealization of Arctic marine animal communities, with decreasing abundance of species with polar affinity and increasing abundance of boreal species (Hoegh-Guldberg \& Bruno, 2010; Fossheim et al., 2015). In contrast, overall species abundance in semi-enclosed seas (i.e., the Mediterranean Sea, Baltic Sea) and tropical ocean basins are expected to decline in the future changing ocean (Cheung et al., 2013).

Modeling climate change impacts on marine ecosystems at a global scale is a relatively new research field, with many global marine ecosystem models only developed in the past decade (Maury, 2010; Blanchard et al., 2012; Cheung et al., 2013; Christensen et al., 2015; Jennings \& Collingridge, 2015; Carozza, Bianchi \& Galbraith 2016). Using outputs (e.g., temperature, currents, primary productivity, ice cover) from global Earth system models (ESMs) forced by projected greenhouse gas emissions and concentrations scenarios, such marine ecosystem models can derive global ocean patterns of biological changes. So far, most studies have forced a single marine ecosystem model using one or several ESMs (Cheung, Dunne, Sarmiento, \& Pauly, 2011; Barange et al. 2012; Blanchard et al. 2012; Jones, Dye, Pinnegar, Warren, \& Cheung, 2015), which can considerably underestimate the range of projection uncertainty by not accounting for the variability due to differing representations of the 
underlying marine ecosystem. To address this limitation, it is important to compare models and to combine them into ensemble projections, which can lead to a better understanding of the sources of uncertainty, provide more coherent projections to policy-makers that properly account for this uncertainty, and thus advance the field of marine ecosystem modeling. While such comparisons are technically challenging, they can inform our understanding of the strengths and weaknesses of each modeling approach and help to guide further model improvements and ultimately improve projections of plausible futures (Schellnhuber, Frieler, \& Kabat, 2013; Tittensor et al., 2018a).

Here we used models in the Fisheries and Marine Ecosystem Model Intercomparison Project (Fish-MIP), an international network that brings together different marine ecosystem modeling approaches (Tittensor et al. 2018a), to better understand and forecast long-term climate change impacts on fisheries and marine ecosystems at ocean basin scales. Specifically, we analyzed how consistent or different mean trends and the spread of model projections were across ocean basins. We used six different global marine ecosystem models, forced by two different ESMs and two greenhouse gas emissions scenarios, to analyze future changes in total marine animal biomass, and the biomass of three marine animal size-classes to explore changes in ecosystem structure, across seven major ocean basins around the globe. The six ecosystem models are founded on a broad range of assumptions, from macroecological concepts focusing on size groups or body mass classes to species-distribution models based on commercially exploited species. Our aims were to (1) improve our understanding of climate change induced trajectories of marine animal biomass in different regions of the future ocean over the $21^{\text {st }}$ century; and (2) facilitate marine ecosystem model advances through model intercomparison across different ocean basins.

This article is protected by copyright. All rights reserved. 


\section{MATERIALS AND METHODS}

\section{Data sources}

Historical (1970-2005) and future (2006-2100) projections of unfished global marine animal biomass (total animal biomass, biomass $>10 \mathrm{~cm}$, biomass $10-30 \mathrm{~cm}$, and biomass $>30 \mathrm{~cm}$; vertebrates and invertebrates of trophic level $>1$, except for zooplankton) under different climate change scenarios were extracted from the Fisheries and Marine Ecosystem Model Intercomparison Project (Fish-MIP v1.0; Tittensor et al. 2018a, b; Data access: http://doi.org/10.5880/PIK.2018.005). The projections included outputs from six different global marine ecosystem models (Table S1): BOATS (Carozza, Bianchi \& Galbraith 2016; Carozza, Bianchi \& Galbraith 2017), Macroecological (Jennings \& Collingridge, 2015), DPBM (Blanchard et al., 2012), DBEM (Cheung et al., 2011), EcoOcean (Christensen et al., 2015), and APECOSM (Maury, 2010). Each marine ecosystem model was forced with standardized output from two Earth system models (ESMs; Table S2) and greenhouse gas emissions scenarios (Representative Concentration Pathways, RCPs) following the Fish-MIP simulation protocol (Tittensor et al., 2018a). ESM outputs were derived from the CMIP5 database (https://esgf-node.llnl.gov/search/cmip5/) and bracketed a wide range of projected climate system changes, with GFDL-ESM2M representing moderate and IPSL-CM5A-LR strong changes in, for example, sea surface temperature and oceanic primary productivity (Bopp et al., 2013). ESM outputs were post-processed to provide forcing inputs at the temporal and spatial resolution required by the ecosystem models (typically one degree spatial resolution and one month or one year temporal resolution, and vertically integrated or vertically specific variables; Table S1, S2). Which specific ESM output variables were used and how each was implemented depended on the respective ecosystem model. For example, DBEM used SST, NPP, zooplankton carbon concentration, current speed, dissolved oxygen, $\mathrm{pH}$, and salinity to model changes in species' habitat suitability (Table S1, S2). In contrast, 
the Macroecological model used changes in NPP and water temperature to model changes in production of size-structured pelagic communities. Specific details for each ecosystem model, including the spatial, vertical, and temporal resolution of forcing variables are given in Tables $\mathrm{S} 1$ and $\mathrm{S} 2$.

For this study, we selected two contrasting emissions scenarios: RCP2.6 characterizes a low emissions or high climate change mitigation scenario, assuming that greenhouse gas emissions peak at 2010-2020 and decline substantially until 2100 (van Vuuren et al., 2011); RCP8.5 characterizes a high emissions pathway assuming a continuous increase in emissions until 2100 while not including specific climate change mitigation targets (Riahi et al., 2011).

As projections including fishing impacts were only available for three marine ecosystem models, and spatially explicit future fisheries projections are as yet unavailable, we chose to focus on runs under a no-fishing scenario, thus isolating climate change effects on marine animal biomass (Tittensor et al., 2018a).

\section{Data analysis}

Projected time-series for historical and future marine animal biomass $\left(\mathrm{g} \mathrm{C} \mathrm{m}^{-2}\right)$ for BOATS, Macroecological, DPBM, DBEM, EcoOcean, and APECOSM were extracted on a 1x1 degree spatial grid for seven ocean basins: North Atlantic Ocean, South Atlantic Ocean, North Pacific Ocean, South Pacific Ocean, Indian Ocean, Arctic Ocean, and Southern Ocean (Figure 1). The forcing variables of sea surface temperature $\left(\mathrm{SST} ;{ }^{\circ} \mathrm{C}\right)$ and net primary production (NPP; mol m $\mathrm{m}^{-3} \mathrm{~s}^{-1}$ ) from GFDL-ESM2M and IPSL-CM5A-LR were extracted for the same ocean basins over the same time scales.

For the ocean basin data subsetting, we selected each grid cell centroid located within the respective ocean basin boundaries using ArcMap 10.5 (ESRI, Redlands, USA, 2017) and 
combined the individual cells into an ocean basin annual mean using the statistical software $\mathrm{R}$ 3.4.3 (R Core Team, 2017).

\section{Temporal changes in marine animal biomass, SST, and NPP}

The marine ecosystem models included in this study account for different species, sizeclasses or trophic groups of marine animals (Table S1; Tittensor et al., 2018a). Hence for each ocean basin and individual marine ecosystem model-ESM combination we calculated proportional biomass change time-series by deriving annual mean changes in total marine animal biomass relative to the average of the 1990-1999 (as a historical reference period). These individual time-series of relative change were then averaged to derive an ensemble mean change. We also calculated proportional biomass changes for each ocean basin in the 2090s relative to the 1990s. A similar approach was used for SST and NPP forcing data. As our measure of variability around the ensemble mean of marine animal biomass projections we used a one inter-model standard deviation.

\section{Model agreement in projected biomass changes}

Model agreement in projected total biomass changes was assessed for the complete ensemble of all ecosystem model-ESM combinations. As measures of model agreement, we used a robustness index (ensemble mean/inter-model standard deviation; Bopp et al. 2013) as well as the percent model agreement in the direction (increase or decrease) of projected changes in the 2090s relative to 1990s. A robustness index >1 indicated high robustness (SD < mean) and an index $<1$ low robustness $(\mathrm{SD}>$ mean) in marine animal biomass projections across ecosystem models (Bopp et al. 2013). For the percent model agreement, 80-100\% of models agreeing on the direction of change in marine animal biomass change was assumed to represent high agreement in the ensemble projections (Bopp et al., 2013). 
Sources of variability in ensemble projections

We compared the relative variability or inter-model spread in projected total marine animal biomass changes due to variability in (i) the different ESMs and (ii) the different marine ecosystem models under the low and high emissions scenarios (RCP 2.6 and RCP8.5). For i) we calculated the mean standard deviation between individual ecosystem model results forced by GFDL-ESM2M and IPSL-CM5A-LR ( $\mathrm{n}=4$ : for marine ecosystem models forced by both ESMs). Next, we calculated the mean standard deviation across ecosystem models to derive the mean variability in our ensemble projections due to ESMs. For ii) we calculated the inter-model standard deviation of marine ecosystem models for GFDL-ESM2M and IPSL-CM5A-LR separately. Then we calculated the mean of the standard deviations from both ESMs for each ocean basin to derive the variability due to marine ecosystem models.

\section{Changes in animal size structure}

To examine climate change impacts on ecosystem structure, we analyzed differences in climate change impacts under RCP2.6 and RCP8.5 on the biomass of marine animals in small $(0-10 \mathrm{~cm})$, medium $(10-30 \mathrm{~cm})$ and large $(>30 \mathrm{~cm})$ size-classes. Because DBEM did not distinguish between size-classes, this model was excluded from this analysis. Ecosystem models that modeled different biomass size-classes account for growth and movement between the size-classes (BOATS: Carozza et al., (2016); EcoOcean: Christensen et al., (2015); DPBM: Blanchard et al., 2011; APECOSM: Maury (2010)). The only exception being the Macroecological model, in which movements of individuals between size-classes was not considered as it is a static representation of the system (Jennings \& Collingridge, 2015). Moreover, since BOATS did not have any size-classes $<10 \mathrm{~cm}$, we could not calculate a small size-class for this model but included it in the medium and large size-classes. Note that excluding BOATS from the small-size class data set did not alter the overall results. For 
each distinct size-class, we calculated the percent relative change in biomass in the 2090s relative to the 1990s for each ecosystem-ESM combination and used box plots to derive the ensemble mean, median and inter-model variation.

\section{Climate change mitigation effect on biomass changes}

Finally, we assessed climate change mitigation effects on projected changes in total marine animal biomass for the model ensemble and individual ecosystem model-ESM means by subtracting the annual mean biomass change under RCP8.5 from RCP2.6. The obtained values represent the climate change mitigation effect in terms of the difference between the projected percentage changes in total animal biomass under the high mitigation scenario (RCP2.6) and the no mitigation/high emissions scenario (RCP8.5).

\section{RESULTS}

Temporal changes in marine animal biomass, SST, and NPP

Our ensemble projections suggest that, in an unfished ocean and hence all impacts due entirely to changes in climate, total animal biomass in all basins except the polar oceans would be consistently lower by the end to the $21^{\text {st }}$ century than at the beginning of the timeseries under both low (RCP2.6; Figure 2) and high (RCP8.5; Figure 3) emissions scenarios (Table 1). Under RCP2.6, ensemble projections of total animal biomass in the North Atlantic and North Pacific Oceans projected sharp declines until 2040 (North Atlantic: 13\%; North Pacific: 10\%) and levelled off afterwards until 2100 (Figure 2). In the South Pacific, South Atlantic and Indian Oceans, lower rates of decline in total animal biomass were projected under RCP2.6 (Figure 2). In contrast, under RCP8.5, projected changes in total animal biomass reached $>20 \%$ declines in the North Atlantic and North Pacific, and 10-20\% declines 
in the South Atlantic, South Pacific and Indian Oceans until 2100 relative to the 1990s (Figure 3).

In the polar ocean basins, trends in ensemble biomass projections differed. In the Arctic Ocean, projected total animal biomass increased until the 2040s under both emissions scenarios. In subsequent years biomass changes stabilized under RCP2.6 (Figure 2) but started to decrease under RCP8.5 (Figure 3). Given the rate of increase until the 2040s, total animal biomass in the Arctic Ocean was projected to increase by $45 \%$ ( $\pm 94 \%$ standard deviation) under RCP2.6 and 80\% ( $\pm 200 \%)$ under RCP8.5 in the 2090s relative to the 1990 s (Table 1). While all 10 ecosystem-ESM combinations projected increases in animal biomass in the Arctic Ocean by the end of the $21^{\text {st }}$-century under RCP2.6, only half did so under RCP8.5 (Figure S3, S4; Table S3). However, the magnitude of projected biomass changes in the Arctic varied substantially across models as indicated by the high inter-model standard deviation. In particular, DBEM projected substantially higher increases in animal biomass in the Arctic relative to the other models (Figure S4), while the variability of projections among the other models was smaller. In the Southern Ocean, projections of total animal biomass showed relatively high variability throughout most of the time-series under both emissions scenarios; however, towards the end of the $21^{\text {st }}$ century, ensemble projections indicated a 10\% decline under RCP2.6 (Figure 2) and an 15\% increase under RCP8.5 (Figure 3).

The temporal trends in projected total animal biomass generally corresponded to a combination of historical and future changes in net primary production (NPP) and sea surface temperature (SST) generated by the ESMs. Under RCP2.6, SST in all basins except the polar oceans was projected to increase by $\sim 1^{\circ} \mathrm{C}$ until the 2040 s and level off until 2100 , with total animal biomass showing a corresponding 5-10\% decline (Figure 2). NPP was projected to initially decrease by 3-10\% until 2030 and either levelled off or increased in the North Atlantic and Pacific, the South Pacific, and Indian Ocean until 2100 (Figure 2). NPP 
projections under RCP2.6 in the South Atlantic Ocean did not show a clear trend throughout most of the $21^{\text {st }}$ century, however, increased by $1-2 \%$ towards the end of the $21^{\text {st }}$ century (Figure 2).

Under RCP8.5, ensemble projections of total animal biomass declined continuously until 2100 in the Atlantic Ocean (North Atlantic: 29\%; South Atlantic: 13\%), Pacific Ocean (North Pacific: 25\%; South Pacific: 18.5\%) and Indian Ocean (19\%). Over the same period, SST was projected to continuously increase and NPP to continuously decrease, except in the South Atlantic for the latter (North Atlantic: $+3.5^{\circ} \mathrm{C}$ and $13 \%$ decline in NPP; North Pacific: $+4.1^{\circ} \mathrm{C}$ and 9\% decline in NPP; South Pacific: $+3.2^{\circ} \mathrm{C}$ and $5 \%$ decline in NPP; Indian Ocean: $+3.3^{\circ} \mathrm{C}$ and 6\% decline in NPP; Figure 3). In the South Atlantic Ocean, total animal biomass was projected to decline by more than $10 \%$ until the end of the $21^{\text {st }}$ century with no substantial concurrent decline in NPP $(0.36 \%)$ yet an SST increase of $+3.4^{\circ} \mathrm{C}$ (Figure 3 ).

In the Arctic Ocean under RCP2.6, SST was projected to increase by $0.5^{\circ} \mathrm{C}$ by the $2030 \mathrm{~s}$ and level off until 2100. NPP projections were relatively variable inter-annually (Figure 2, S2) but correlated with the projected SST changes by the end of the $21^{\text {st }}$ century (Figure 2; Figure S1). Under RCP8.5, projections of SST continuously increased up to $2^{\circ} \mathrm{C}$ by 2100 (Figure 3 ). NPP showed a projected $25 \%$ increase until the 2040s with a $6 \%$ decrease thereafter, which correlated with the projected trend in total animal biomass changes (Figure 3). In the Southern Ocean, projected trends in SST and NPP under RCP2.6 were highly variable with no evidence for an underlying trend. This was reflected in the projected trends in total animal biomass (Figure 2). Patterns in projected SST, NPP and total animal biomass were similar under RCP8.5 (Figure 3).

This article is protected by copyright. All rights reserved. 


\section{Model agreement in projected biomass changes}

Our metrics of model agreement within the model ensemble revealed high robustness $(>1)$ and high percentage model agreement in the direction of projected biomass changes ( $>80$ $100 \%$ ) in all basins except the polar basins under both emissions scenarios (Table 1). For both RCP2.6 and RCP8.5 the highest robustness index of $>2$ was found in the North Atlantic Ocean (Table 1). In contrast, projections in the polar ocean basins under both emissions scenarios had low robustness indices $(<1)$. Model agreement in the direction of change was high in both polar oceans under RCP2.6, but only in the Southern Ocean under RCP8.5 (Table 1). In the Arctic Ocean, under RCP8.5 only 50\% of the included ecosystem models agreed on the direction of change in projected total animal biomass (Table 1, S3; Figure S3, S4).

Model spread, represented as one inter-model standard deviation of the ensemble mean, was lower under RCP2.6 than RCP8.5 across all ocean basins (Table 1, Figure S3). Model spread ranged from \pm 3 to $6 \%$ under RCP2.6 across all basins except for the Arctic Ocean with $\pm 94 \%$ (Table 1). Under RCP8.5, model spread was higher, ranging from \pm 12 to $17 \%$ in all ocean basins except for $\pm 35 \%$ for the Southern Ocean and $\pm 200 \%$ for the Arctic Ocean (Table 1).

\section{Sources of variability in ensemble projections}

Projections forced by GFDL-ESM2M and IPSL-CM5A-LR differed between most ocean basins (i.e., North Atlantic, North Pacific, Southern Ocean, Arctic Ocean; Figure S3). However, the mean variability in total marine animal biomass projections under both emissions scenarios due to the ESMs was of similar magnitude to the mean variability due to the marine ecosystem models across all ocean basins (RCP2.6: 2-7\%; RCP8.5: 4-10\%) except in the Arctic Ocean (Figure S5). In the Arctic Ocean, mean variability of total animal biomass projections due to the marine ecosystem models was $\sim 40 \%$ greater under RCP2.6 
and $\sim 70 \%$ greater under RCP8.5 than the mean variability due to the different ESMs (Figure S5).

\section{Changes in animal size structure}

Our analysis of relative changes in the projected biomass of animals in different size-classes (large-sized animals: $>30 \mathrm{~cm}$, medium-sized animals: $10-30 \mathrm{~cm}$, small-sized animals $<10 \mathrm{~cm}$ ) showed that projected biomass in all size-classes decreased in the Pacific, Atlantic and Indian Ocean basins under RCP8.5 by the end of the $21^{\text {st }}$ century (Figure 4$)$. In the North and South Atlantic Ocean, a greater decrease in the mean biomass of medium-sized animals (North Atlantic: 29\%; South Atlantic: 17\%) was projected compared to small animals (North Atlantic: 24.5\%; South Atlantic: 10\%) and large (North Atlantic: 24\%; South Atlantic: 12\% ) (Figure 4). The reverse was observed in the North Pacific Ocean, with mean projected biomass decreases of $13.5 \%$ in medium-sized animals, while biomass of large and small animals decreased by $21 \%$ and $23 \%$ respecitvely (Figure 4 ). The overall trends in the South Pacific Ocean did not change substantially across size-classes (small-sized animals: 13\%; medium-sized animals: 12\%; large-sized animals: 12\%; Figure 4). Similarly, in the Indian Ocean, projected trends in biomass under RCP8.5 did not differ substantially among sizeclasses (small-sized animals: 13.5\%; medium-sized animals: 12\%; large-sized animals: 14\%; Figure 4). In contrast, the biomass of animals in all size-classes in the Southern Ocean were projected to increase by the end of the $21^{\text {st }}$ century, with mean biomass of large animals projected to increase by $\sim 10 \%$, medium-sized animals by $5 \%$, and small animals by $3 \%$ (Figure 4). In the Arctic Ocean, only biomass of large animals was projected to increase (by $5 \%$ ), while mean biomass of medium-sized animals decreased by $10 \%$ and biomass of small animals by $5 \%$ (Figure 4$)$.

This article is protected by copyright. All rights reserved. 
Under RCP2.6, biomass of all three size-classes in the Arctic Ocean was projected to increase, ranging from $15 \%$ for large animals to $5-7 \%$ for the medium and small size-classes, while only large animal biomass was projected to increase (2\%) in the Southern Ocean (Figure S6). The trends in projected biomass in different size-classes in the Pacific, Atlantic and Indian Ocean basins under RCP2.6 were similar in direction but smaller in magnitude than trends under RCP8.5 (Figure 4, S6).

\section{Climate change mitigation effect on biomass changes}

The climate change mitigation effect on projected ensemble mean changes in total marine animal biomass was minor until 2050 in all ocean basins (mean mitigation effect over 20062049: $+0.02 \%, \pm 1.87 \%$; Figure 5) except for the Arctic Ocean, where climate change mitigation was projected to lead to greater increases in mean animal biomass under the high mitigation scenario (RCP2.6) than under the no mitigation scenario (RCP8.5) until 2050 (mean mitigation effect over 2006-2049: $+10.5 \%, \pm 7.4 \%$; Figure 5). After 2050, climate change mitigation was projected to have a positive effect on biomass changes in most ocean basins, meaning climate change mitigation would dampen projected climate change induced biomass decreases (mean mitigation effect over 2050-2100: North Atlantic: 13\%, $\pm 5 \%$; South Atlantic: $5 \%, \pm 2 \%$; North Pacific: $10 \%, \pm 4 \%$; South Pacific: $7 \%, \pm 3 \%$; Indian Ocean: $9 \%$, $\pm 4 \%$; Figure 5). However, for the Arctic and Southern Ocean, climate change mitigation reduced the projected biomass increase towards the end of the $21^{\text {st }}$ century (mean mitigation effect over 2050-2100: Arctic Ocean: -28\%, $\pm 13 \%$; Southern Ocean: -7\%, $\pm 6 \%$; Figure 5).

Climate change mitigation effects on total animal biomass projections from 2050-2100 differed notably in magnitude between individual ecosystem models in all ocean basins except in the North Atlantic and South Pacific Ocean (Figure S7). BOATS, Macroecological, and DBEM showed the largest climate change mitigation effects from 2050-2100 in all ocean 
basins except polar basins, ranging from $9-13 \%( \pm 3-5 \%)$ for BOATs to $6-20 \%( \pm 4-8 \%)$ for the Macroecological model, and 8-17\% ( $\pm 3-7 \%)$ for DBEM. In comparison, mean climate change mitigation effects from 2050-2100 reached 4-5\% ( $\pm 2 \%)$ for APECOSM, 3-4\% ( \pm 1 $2 \%$ ) for DPBM, and 2-9\% ( $\pm 1-3 \%)$ for EcoOcean. In the Arctic and Southern Ocean, climate change mitigation effects from 2050-2100 differed in magnitude and trend compared to the other basins (Figure S7). Notably, in the Arctic Ocean all models, except for DBEM, showed a mean positive climate change mitigation effect ranging from $4-10 \%( \pm 4-7 \%)$, while that for DBEM was $-172 \%( \pm 54 \%)$. In the Southern Ocean, most models showed a negative climate change mitigation effect from 2050-2100, with DBEM showing a larger mitigation effect of $-28 \%( \pm 23 \%)$ than the other models (APECOSM $-3 \%( \pm 4 \%)$, BOATS $-1.5 \%( \pm 2)$, DPBM $0.2 \%( \pm 2.5 \%)$, Macroecological model -3\% ( $\pm 4 \%)$, EcoOcean $-4 \%( \pm 5 \%)$ ).

\section{DISCUSSION}

Our ensemble models projected consistently lower marine animal biomass by the end of the $21^{\text {st }}$ century compared to the end of the $20^{\text {th }}$ century in all ocean basins except the polar oceans, where mean marine animal biomass was projected to increase, though with substantial variability between models. Variation around ensemble projections was generally lower under the strong climate change mitigation scenario (RCP2.6) than the high emissions scenario (RCP8.5), and highest in the Arctic Ocean compared to all other ocean basins. Although we do not explicitly simulate mitigation pathways, our results based on the difference between RCP2.6 and RCP8.5 suggest that effective climate change mitigation policies have the potential to substantially lower the magnitude of climate change impacts on marine animal biomass across all ocean basins through 2100.

This article is protected by copyright. All rights reserved. 


\section{Ensemble projections in different ocean basins}

In the North Atlantic and North Pacific, projected total marine animal biomass declined less under the strong mitigation (RCP2.6, 10\% decline) than the high emissions scenario (RCP8.5, $20 \%$ decline), in line with the lower magnitude of projected changes in SST (RCP2.6: $\sim 1^{\circ} \mathrm{C}$ increase; RCP8.5: 3-4 ${ }^{\circ} \mathrm{C}$ increase) and NPP (RCP2.6: 3-5\% decrease; RCP8.5: 8-13\% decrease). In the South Atlantic, South Pacific and Indian Ocean, projected biomass declines were similar under RCP8.5 ( 20\%) yet reached only $\sim 5 \%$ under RCP2.6 by the mid- $21^{\text {st }}$ century and levelled off afterwards. In these three ocean basins, projected NPP decreased less than in the North Atlantic and North Pacific, which is primarily due to differences in stratification and nutrient supply regimes in the Earth system models (ESMs) used to force the marine ecosystem models in this study (Doney, 2010; Capotondi, Alexander, Bond, Curchitser, \& Scott, 2012; Dunne et al. 2012, Dufresne et al. 2013). Thus, the differences in projected biomass declines between the two emissions scenarios can be partially explained by differences in environmental drivers the modelled marine organisms experience in the simulated future ocean, such as effects on the physiology of marine organisms (e.g. metabolic rates, growth, survival and trophic interactions) and availability of habitat (Cheung et al. 2009; Fu, Randerson, \& Moore, 2016; Worm \& Lotze 2016). If a habitat becomes unsuitable for a given population, for example due to thermal stress, population size may decline as ecophysiological performance is negatively affected or species may shift their distribution to cooler waters (Pörtner, 2001; Pörtner \& Knust, 2007; Cheung, Watson, \& Pauly, 2013). These effects play out differently in the different ecosystem models due to their varying structures and characterization of processes (Tittensor et al. 2018a), thus influencing the projected biomass trends. For example, projections by the species distribution model DBEM are strongly affected by changes in the availability of suitable habitat due to shifting temperature fields, ice cover and primary production. In comparison, biomass dynamics in 
the size-structured models are driven by size-dependent processes such as production and energy transfer (Macroecological, BOATS) or detailed size-dependent feeding processes, growth and mortality (DPBM) and size-dependent movement (APECOSM) which are all affected by changes in environmental forcing variables (Table S2).

Ensemble projections in the Arctic suggested a $60 \%$ increase of total animal biomass until the mid- $21^{\text {st }}$ century followed by a stabilization under RCP 2.6 and a decrease of $80 \%$ under RCP8.5 towards the end of the $21^{\text {st }}$ century. In the Southern Ocean, conversely, ensemble projections showed only a slight biomass decrease $(\sim 10 \%)$ towards the end of the $21^{\text {st }}$ century under RCP2.6 yet a continuous increase to $\sim 15 \%$ under RCP8.5. The projected biomass increases in polar oceans until the mid- $21^{\text {st }}$ century can be attributed to processes such as immigrating marine animals from warmer waters as new habitats become available (Cheung et al., 2009), increasing water temperatures and primary production enhancing growth and survival (Frainer et al., 2017), and longer growing seasons influencing phenology (Racault, Le Quéré, Buitenhuis, Sathyendranath, \& Platt, 2012). In our ecosystem model ensemble, the magnitude of the mean biomass increases in both the Arctic and Southern Ocean were primarily influenced by DBEM, which models species-specific habitats for commercial fish and invertebrates (Cheung et al. 2011). In the 1990s (our historical reference period), DBEM has only a few commercial species with relatively low biomass levels in the Arctic and Antarctic; thus, any newly invading commerical species and increasing growth results in large proportional changes in biomass. Thus, these results can be partly explained by the specific focus of this model. In contrast, all other ecosystem models (Macroecological, BOATS, DPBM, EcoOcean, and APECOSM) project bulk changes in marine animal biomass across different size-classes, functional and trophic groups due to changes in environmental factors affecting metabolic rates, energy transfer as well as trophic relationships (see Table S1) and can include commercial and non-commercial species. Therefore, these models 
generally start with higher initial biomass in polar oceans meaning that proportional changes in the future are lower

In the second half of the $21^{\text {st }}$ century, the projected stabilization of biomass changes in the Arctic and Southern Ocean under RCP2.6 can be explained by changes in the forcing variables driven by strong climate change mitigation policies (van Vuuren et al. 2011), as indicated by the levelling off in projected SST and NPP trends (Figure S1, S2). In contrast, under the high emissions scenario (RCP8.5), in which greenhouse gas emissions are projected to increase until 2100 (Riahi et al. 2011), the decline in projected total marine animal biomass in the Arctic may be attributed to continuing changes in the physical and biogeochemical environment, with consequences for the entire trophic network (Hillebrand et al., 2018). Indeed, longer-term projections of changes in ocean ecosystems until 2300 suggest a strong decline in ocean productivity in the Northern Hemisphere and its shift towards the Southern Ocean (Moore et al. 2018; (Figure 3). In the Arctic, the projected late $21^{\text {st }}$ century biomass decline under RCP8.5 was concurrent with a projected $20 \%$ decline in NPP during that period, likely attributed to enhanced stratification due to changes in water temperature and salinity with melting sea ice and permafrost (Fu, Randerson \& Moore 2016). Large decreases in sea ice cover could also enhance light levels, leading to higher seasonal NPP (Leung, Cabre, \& Marinov, 2015). The loss of sea ice can also directly affect sea ice-dependent marine animals in both the Arctic and Southern Ocean, which rely on sea ice for reproduction, feeding or survival, ranging from krill (Antarctic krill in the Southern Ocean, Calanus copepods in the Arctic) to Arctic cod (Boreogadus saida) to many whale species, such as narwhales (Monodon monoceros) and killer whales (Orcinus orca) (Stenson \& Hammill, 2014; Hillebrand et al., 2018; Macias-Fauria \& Post, 2018). With krill and copepods representing a significant link between phytoplankton and higher trophic levels, sea 
ice loss is expected to lead to substantial modifications in the existing Arctic and Antarctic ecosystems and associated commercial and subsistence fisheries (Mcbride et al., 2014; Moore et al., 2018). However, only half of the marine ecosystem models accounted for changing ice dynamics (Table S2), yet these did not necessarily agree on the direction of biomass change (Figure S3, S4); consequently, it is difficult to determine how much the projected biomass changes in the polar basins are due to changing ice cover and its implications for polar food webs.

\section{Variability around ensemble projections}

We used an ensemble model approach which included six marine ecosystem models forced with two different ESMs and different RCPs to project past and future marine animal biomass under different climate change scenarios (Tittensor et al., 2018a, 2018b). The ensemble approach has the advantage that ecosystem models characterized by different model structure, processes and underlying assumptions are more likely to capture relevant features in complex ocean ecosystems than any single model (Spence et al., 2017; Tittensor et al., 2018a). The ensemble approach also allows for the ability to quantify uncertainties due to marine ecosystem models, which remains important information for policy-makers and managers but is unavailable from single model projections. Here we used metrics including variability around the ensemble mean, a robustness index and model agreement in the direction of change (Bopp et al. 2013; Tittensor et al. 2018a). Comparing results of different ecosystem models can also help to understand how projections are affected by different model structures and ecological processes. Thus, ensemble projections and model inter-comparison projects have emerged as an extremely useful approach in climate impact sciences (Schellnhuber et al. 2013; Spence et al. 2017; Tittensor et al. 2018a).

This article is protected by copyright. All rights reserved. 
High variability and uncertainty of ensemble results were detected in the Arctic and Southern Ocean. As discussed above, this may be partly due to the fact that DBEM projections of changes in habitat and associated population dynamics specifically focused on commercial fish and invertebrates (Cheung et al., 2011; Cheung, Sarmiento et al., 2012), which are currently very low in abundance and may therefore lead to proportionally larger relative biomass changes in these regions due to changes in projected SST, NPP, ice cover, and other environmental variables. However, the general trends in biomass change projected in the polar oceans by DBEM did not differ from most of the other ecosystem models, suggesting broad agreement in the direction of projected changes over the coming century despite varying magnitudes. Overall, a general projected increase in total marine animal biomass in the Arctic and Southern Ocean, yet a decrease in the North and South Atlantic and Pacific and Indian Oceans may occur by the end of the $21^{\text {st }}$ century under both emissions scenarios, which corresponds with the IPCC's Fifth Assessment Report and other single- and multimodel studies (Pörtner et al., 2014; Blanchard et al., 2017).

\section{Changes in ecosystem structure}

In most ocean basins, the greater projected declines in biomass of medium-sized animals may be explained by the decline of their smaller-sized prey. In comparison, the reduced relative declines in the projected biomass of large animals may result from model structures and parameterizations which result in larger animals having access to a larger pool of available food sources (both medium- and small-sized animals), slower turnover times which result in lagged responses to changing ecosystem dynamics, as well as food competition effects due to increasing competition for small-sizes animals with the medium-sized animals (Perry et al., 2005; Lefort et al., 2015). 


\section{Climate change mitigation}

Based on our model ensemble, climate change mitigation that reduces greenhouse gas emissions in line with RCP2.6 (van Vuuren et al. 2011) was projected to lessen the decreases in total marine animal biomass by 10-20\% compared to the high emissions scenario (RCP8.5) in all non-polar oceans, but also dampen increases in polar oceans. Thus, with successful climate change mitigation, declines in marine animal biomass in the North and South Atlantic and Pacific and the Indian Oceans could potentially be alleviated, particularly after the 2050s. This result was consistent across all ecosystem models, only differing in the magnitude of the climate change mitigation effect. Along with recent projections of the mitigation effects on the timing of emergence of climate change impacts on environmental drivers (Henson et al., 2017), our results suggest that climate change impacts on marine ecosystems can be substantially reduced by successfully implementing mitigation measures. In the Arctic and Southern Ocean, climate change mitigation also reduced projected impacts and led to lower changes in biomass, which resulted in reduced proportional biomass increases or even declines. However, the individual ecosystem models showed contrasting trends, with only DBEM projecting substantially reduced biomass increases. As discussed above, this result is likely due to different model structures and taxonomic scope. By slowing the pace of climate change and reducing impacts, climate change mitigation would provide time and opportunity for adaptation and development of proactive ocean policies, such as in the context of marine conservation efforts and fisheries management strategies (Blanchard et al. 2017; Henson et al., 2017).

This article is protected by copyright. All rights reserved. 


\section{Caveats and future steps}

The use of outputs from two ESMs (GFDL-ESM2M and IPSL-CM5A-LR) to force the marine ecosystem models represents a relatively small range of the set of ESMs available. However, as GFDL-ESM2M represents relatively weak and IPSL-CM5A-LR relatively strong changes in sea surface warming and net primary production over the $21^{\text {st }}$ century, they bracket the spread of projections reasonably well (Bopp et al., 2013). Furthermore, most other ESMs in the CMIP5 database do not provide or have not stored the necessary monthly, depth-resolved outputs of different size groups of phyto- and zooplankton required by several of the global marine ecosystem models within Fish-MIP (Tittensor et al., 2018a; Table S2). By choosing two ESMs representing the high and low end of projected future climate change scenarios, our projected mean future change is comparable to the overall CMIP5 ensemble mean (Bopp et al., 2013). Future studies may have the possibility of including a larger range of ESMs and their outputs through the upcoming CMIP6, which will also provide higher resolution of biogeochemical variables (Ruane et al., 2016).

Another caveat is that coastal ecosystems and upwelling areas account for a large proportion of global primary production; however, the ESMs provide limited resolution of physical and biogeochemical processes in these systems (Holt et al., 2017; Bonan \& Doney, 2018). To improve projections of biomass changes in these systems, regional downscaling of global ESMs is desirable to incorporate climate and ecosystem features at a higher resolution (Holt et al., 2017).

This article is protected by copyright. All rights reserved. 
The selected ocean basins comprise areas that range from highly productive regions i.e. nutrient rich upwelling ecosystems (Canary and Benguela Current in the Atlantic Ocean, California and Humboldt Current in the Pacific Ocean) to low productivity regions i.e. warm, nutrient-poor subtropical gyres in the Atlantic, Pacific and Indian Ocean (Hoegh-Guldberg \& Poloczanska, 2017). We acknowledge that our analysis does not account for regionalization within each ocean basin, which might mask substantial regional variation in marine animal biomass under global change. Future research could focus on a region by region scale using the Fish-MIP data to further our understanding on regionalized climate change impacts on marine life.

While our ensemble model projections and analysis of model agreement contribute information on potential future changes in marine animal biomass and the spread of uncertainty around these changes, our study represents only the beginning of a systematic collaborative marine ecosystem model evaluation and intercomparison. To comprehensively improve ecosystem models participating in Fish-MIP, future effort should focus on improving our understanding of the mechanisms that drive individual model responses to forcing variables, such as by separating the forcings temperature and NPP (Carozza et al. in press), evaluating uncertainty within and across models, and attempting to refine individual model predictions under climate change.

\section{Implications and conclusions}

At present, trends in greenhouse gas emissions are consistent with those assumed in the high emissions scenario (RCP8.5; Peters et al., 2012), under which total marine animal biomass was projected to decline by at least $10-20 \%$ in all but the polar ocean basins, where projected biomass increased by at least $15-80 \%$ over the $21^{\text {st }}$ century. Such changes would have socioeconomic and food security impacts on regional and global scales (Pörtner et al., 2014; 
Blanchard et al., 2017). However, we have also demonstrated the level of these changes can be greatly reduced through climate mitigation efforts - such as adopting policies on national and global scales that reduce the sources and enhance the sinks of long-lived anthropogenic greenhouse gases (Bonan \& Doney, 2018) and moving towards meeting international climate mitigation agreements, such as the Paris Agreement within the United Nations Framework Convention on Climate Change.

\section{ACKNOWLEDGEMENTS}

We acknowledge the immense effort of all marine ecosystem modellers who contributed their expertise, time, and feedback to this study and the Fish-MIP initiative, particularly, T. Silva, D. Carozza, D. Bianchi, T. Eddy, N. Barrier, P. Verley, V. Christensen, and J. Steenbeek for running Fish-MIP simulations and providing ecosystem model outputs. We also thank L.

Bopp, J. Dunne, C. Stock, and T. Roy for providing ESM outputs, M. Büchner, J. Volkholz, and J. Schewe for technical support, and D. Boyce for valuable discussions and comments. Financial support was provided by the German Federal Ministry of Education and Research (BMBF, grant no. 01LS1201A1) and through the Inter-Sectoral Impact Model Intercomparison Project (ISI-MIP). ABB acknowledges financial support from the NSERC CREATE Transatlantic Ocean Science and Technology Program, HKL from the Natural Sciences and Engineering Research Council (NSERC) of Canada, and DPT from the Kann Rasmussen Foundation Denmark. The authors declare that they have no conflict of interest. 


\section{REFERENCES}

Barange, M., Merino, G., Blanchard, J. L., Scholtens, J., Harle, J., Allison, E. H., ... Jennings, S. (2014). Impacts of climate change on marine ecosystem production in societies dependent on fisheries. Nature Climate Change, 4(3), 211-216. https://doi.org/10.1038/NCLIMATE2119

Blanchard, J. L., Law, R., Castle, D. C., Jennings, S. (2011). Coupled energy pathways and the resilience of size-structured food webs. Theoretical Ecology, 4(289). https://doi.org/10.1007/s12080-010-0078-9

Blanchard, J. L., Jennings, S., Holmes, R., Harle, J., Merino, G., Allen, J. I., ... Barange, M. (2012). Potential consequences of climate change for primary production and fish production in large marine ecosystems. Philosophical Transactions of the Royal Society of London. Series B, Biological Sciences, 367(1605), 2979-2989. https://doi.org/10.1098/rstb.2012.0231

Blanchard, J. L., Watson, R. A., Fulton, E. A., Cottrell, R. S., Nash, K. L., BryndumBuchholz, A., ... Jennings, S. (2017). Linked sustainability challenges and trade-offs among fisheries, aquaculture and agriculture. Nature Ecology and Evolution, 1(9), 1240-1249. https://doi.org/10.1038/s41559-017-0258-8

Bonan, G. B., \& Doney, S. C. (2018). Climate, ecosystems, and planetary futures: The challenge to predict life in Earth system models. Science, 359(6375). https://doi.org/10.1126/science.aam8328

Bopp, L., Resplandy, L., Orr, J. C., Doney, S. C., Dunne, J. P., Gehlen, M., ... Vichi, M. (2013). Multiple stressors of ocean ecosystems in the 21st century: Projections with CMIP5 models. Biogeosciences, 10(10), 6225-6245. https://doi.org/10.5194/bg-10- 
Boyce, D. G., Lewis, M. R., \& Worm, B. (2010). Global phytoplankton decline over the past century. Nature, 466(7306), 591-596. https://doi.org/10.1038/nature09268

Capotondi, A., Alexander, M. A., Bond, N. A., Curchitser, E. N., \& Scott, J. D. (2012). Enhanced upper ocean stratification with climate change in the CMIP3 models. Journal of Geophysical Research: Oceans, 117(4), 1-23. https://doi.org/10.1029/2011JC007409

Carpenter, S. R., Kitchell, J. F., \& Hodgson, J. R. (1985). Fish predation and herbivory can regulate lake ecosystems. BioScience, 35(10), 634-639. https://doi.org/10.2307/1309989

Carozza, D. A., Bianchi, D., \& Galbraith, E. D. (2016). The ecological module of BOATS1.0: a bioenergetically constrained model of marine upper trophic levels suitable for studies of fisheries and ocean biogeochemistry, Geoscientific Model Development, 9, 1545-1565. https://doi.org/10.5194/gmd-9-1545-2016

Carozza, D. A., Bianchi, D., \& Galbraith, E. D. (2017). Formulation, general features and global calibration of a bioenergetically-constrained fishery model. PLOS ONE 12(1): e0169763. doi:10.1371/journal.pone.0169763

Carozza, D. A., Bianchi, D. \& Galbraith, E. D. (in press). Metabolic impacts of climate change on marine ecosystems: implications for fish communities and fisheries. Global Ecology and Biogeography.

Cheung, W. W. L., Dunne, J., Sarmiento, J. L., \& Pauly, D. (2011). Integrating ecophysiology and plankton dynamics into projected maximum fisheries catch potential under climate change in the Northeast Atlantic. ICES Journal of Marine Science, 68(6), 1008-1018. https://doi.org/10.1093/icesjms/fsr012

This article is protected by copyright. All rights reserved. 
Cheung, W. W. L., Lam, V. W. Y., Sarmiento, J. L., Kearney, K., Watson, R., \& Pauly, D. (2009). Projecting global marine biodiversity impacts under climate change scenarios. Fish and Fisheries, 10(3), 235-251. https://doi.org/10.1111/j.1467-2979.2008.00315.x

Cheung, W. W. L., Lam, V. W. Y., Sarmiento, J. L., Kearney, K., Watson, R., Zeller, D., \& Pauly, D. (2010). Large-scale redistribution of maximum fisheries catch potential in the global ocean under climate change. Global Change Biology, 16(1), 24-35. https://doi.org/10.1111/j.1365-2486.2009.01995.x

Cheung, W. W. L., Pinnegar, J., Merino, G., Jones, M. C., \& Barange, M. (2012). Review of climate change impacts on marine fisheries in the UK and Ireland. Aquatic Conservation: Marine and Freshwater Ecosystems, 22(3), 368-388. https://doi.org/10.1002/aqc.2248

Cheung, W. W. L., Watson, R., \& Pauly, D. (2013). Signature of ocean warming in global fisheries catch. Nature, 497(7449), 365-368. https://doi.org/10.1038/nature12156

Christensen, V., Coll, M., Buszowski, J., Cheung, W. W. L., Frölicher, T., Steenbeek, J., ... Walters, C. J. (2015). The global ocean is an ecosystem: Simulating marine life and fisheries. Global Ecology and Biogeography, 24(5), 507-517. https://doi.org/10.1111/geb.12281

Doney, S. C. (2010). The growing human footprint on coastal and open-ocean biogeochemistry. Science, 328(5985), 1512-1516. https://doi.org/10.1126/science.1185198

Dufresne, J. L., Foujols, M. A., Denvil, S., Caubel, A., Marti, O., Aumont, O., ... \& Bony, S. (2013). Climate change projections using the IPSL-CM5 Earth System Model: from CMIP3 to CMIP5. Climate Dynamics, 40(9-10), 2123-2165. 
Dunne, J. P., John, J. G., Adcroft, A. J., Griffies, S. M., Hallberg, R. W., Shevliakova, E., ... \& Krasting, J. P. (2012). GFDL's ESM2 global coupled climate-carbon earth system models. Part I: Physical formulation and baseline simulation characteristics. Journal of Climate, 25(19), 6646-6665.

ESRI 2017. ArcGIS Desktop: Release 10.5. Redlands, CA: Environmental Systems Research Institute.

Fossheim, M., Primicerio, R., Johannesen, E., Ingvaldsen, R. B., Aschan, M. M., \& Dolgov, A. V. (2015). Recent warming leads to a rapid borealization of fish communities in the Arctic. Nature Climate Change, 5, 673-677. https://doi.org/10.1038/nclimate2647

Frainer, A., Primicerio, R., Kortsch, S., Aune, M., Dolgov, A. V., Fossheim, M., \& Aschan, M. M. (2017). Climate-driven changes in functional biogeography of Arctic marine fish communities. Proceedings of the National Academy of Sciences, 114(46), 12202-12207. https://doi.org/10.1073/pnas.1706080114

Frederiksen, M. (2017). Synthesis: Status and trends of Arctic marine biodiversity and monitoring. State of the Arctic Marine Biodiversity Report, 175-193. CAFF International Secretariat.

Fu, W., Randerson, J. T., \& Keith Moore, J. (2016). Climate change impacts on net primary production (NPP) and export production (EP) regulated by increasing stratification and phytoplankton community structure in the CMIP5 models. Biogeosciences, 13(18), 5151-5170. https://doi.org/10.5194/bg-13-5151-2016

Galbraith, E. D., Carozza, D. A., \& Bianchi, D. (2017). A coupled human-Earth model perspective on long-term trends in the global marine fishery. Nature Communications, 8 , 1-7. https://doi.org/10.1038/ncomms14884

This article is protected by copyright. All rights reserved. 
Harnik, P. G., Lotze, H. K., Anderson, S. C., Finkel, Z. V., Finnegan, S., Lindberg, D. R., ... Tittensor, D. P. (2012). Extinctions in ancient and modern seas. Trends in Ecology and Evolution, 27(11), 608-617. https://doi.org/10.1016/j.tree.2012.07.010

Henson, S. A., Beaulieu, C., Ilyina, T., John, J. G., Long, M., Séférian, R., ... Sarmiento, J. L. (2017). Rapid emergence of climate change in environmental drivers of marine ecosystems. Nature Communications, 8(5020), 1-9. https://doi.org/10.1038/ncomms14682

Hillebrand, H., Brey, T., Gutt, J., Hagen, W., Metfies, K., Meyer, B., \& Lewandowska, A. (2018). Climate Change: Warming Impacts on Marine Biodiversity. In Salomon M., Markus T. (eds) Handbook on Marine Environment Protection, 353-373. https://doi.org/10.1007/978-3-319-60156-4_18

Hoegh-Guldberg, O., \& Bruno, J. F. (2010). The impact of climate change on the world's marine ecosystems. Science, 328(5985), 15231528.https://doi.org/10.1126/Science. 1189930

Hoegh-Guldberg O and Poloczanska ES (2017) Editorial: The Effect of Climate Change across Ocean Regions. Front. Mar. Sci. 4:361. doi: 10.3389/fmars.2017.00361

Holt, J., Hyder, P., Ashworth, M., Harle, J., Hewitt, H. T., Liu, H., ... Wood, R. (2017). Prospects for improving the representation of coastal and shelf seas in global ocean models. Geoscientific Model Development, 10(1), 499-523. https://doi.org/10.5194/gmd-10-499-2017

IHO 23-3rd: Limits of Oceans and Seas, Special Publication 23, 3rd Edition 1953, published by the International Hydrographic Organization.

Jennings, S., \& Collingridge, K. (2015). Predicting consumer biomass, size-structure, 
production, catch potential, responses to fishing and associated uncertainties in the world's marine ecosystems. PLoS ONE, 10(7), 1-28.

https://doi.org/10.1371/journal.pone.0133794

Jennings, S. and Blanchard, J. L. (2004), Fish abundance with no fishing: predictions based on macroecological theory. Journal of Animal Ecology, 73(4), 632-642. https://doi.org/10.1111/j.0021-8790.2004.00839.x

Jones, M. C., Dye, S. R., Pinnegar, J. K., Warren, R., \& Cheung, W. W. L. (2015). Using scenarios to project the changing profitability of fisheries under climate change. Fish and Fisheries, 16(4), 603-622. https://doi.org/10.1111/faf.12081

Le Bris, A., Mills, K. E., Wahle, R. A., Chen, Y., Alexander, M. A., Allyn, A. J., ... Pershing, A. J. (2018b). Climate vulnerability and resilience in the most valuable North American fishery. Proceedings of the National Academy of Sciences, 115(8), 1831-1836. https://doi.org/10.1073/pnas.1711122115

Lefort, S., Aumont, O., Bopp, L., Arsouze, T., Gehlen, M., \& Maury, O. (2015). Spatial and body-size dependent response of marine pelagic communities to projected global climate change. Global Change Biology, 21(1), 154-164. https://doi.org/10.1111/gcb.12679

Leung, S., Cabre, A., \& Marinov, I. (2015). A latitudinally banded phytoplankton response to 21st century climate change in the Southern Ocean across the CMIP5 model suite. Biogeosciences, 12(19), 5715-5734. https://doi.org/10.5194/bg-12-5715-2015

Lotze, H. K., Tittensor, D. P., Bryndum-Buchholz, A., Eddy, T. D., Cheung, W. L., Galbraith, E. D., ... Walker, N. D. Ensemble projections of global ocean animal biomass with climate change. (in review)

Macias-Fauria, M., \& Post, E. (2018). Effects of sea ice on Arctic biota: an emerging crisis 
discipline. Biology Letters, 14(3), 20170702. https://doi.org/10.1098/rsbl.2017.0702

Maury, O. (2010). An overview of APECOSM, a spatialized mass balanced "Apex Predators ECOSystem Model" to study physiologically structured tuna population dynamics in their ecosystem. Progress in Oceanography, 84(1-2), 113-117. https://doi.org/10.1016/j.pocean.2009.09.013

Mcbride, M. M., Dalpadado, P., Drinkwater, K. F., Godø, O. R., Hobday, A. J., Hollowed, A. B., ... Loeng, H. (2014). Krill, climate, and contrasting future scenarios for Arctic and Antarctic fisheries. ICES Journal of Marine Science, 71(7), 1934-1955. https://doi.org/10.1093/icesjms/fsu002

Moore, J. K., Fu, W., Primeau, F., Britten, G. L., Lindsay, K., Long, M., ... Randerson, J. T. (2018). Sustained climate warming drives declining marine biological productivity, Science, 359(6380), 1139-1143. http://doi.org/10.1126/science.aao6379

Ojea, E., Pearlman, I., Gaines, S. D., \& Lester, S. E. (2017). Fisheries regulatory regimes and resilience to climate change. Ambio, 46(4), 399-412. https://doi.org/10.1007/s13280016-0850-1

Pecl, G. T., Araújo, M. B., Bell, J. D., Blanchard, J., Bonebrake, T. C., Chen, I. C., ... Williams, S. E. (2017). Biodiversity redistribution under climate change: Impacts on ecosystems and human well-being. Science, 355(6332). https://doi.org/10.1126/science.aai9214

Perry, a. L. (2005). Climate change and distribution shifts in Mmrine fishes. Science, 308(5730), 1912-1915. https://doi.org/10.1126/science.1111322

Peters, G. P., Andrew, R. M., Boden, T., Canadell, J. G., Ciais, P., Quéré, C. Le, ... Wilson, C. (2012). The challenge to keep global warming below 2 C. Nature Climate Change, 
3(1), 2-4. https://doi.org/10.1038/nclimate1783

Pinsky, M. L., \& Mantua, N. J. (2014). Emerging adaptation approaches for climate-ready fisheries management. Oceanography, 27(4), 146-159.

https://doi.org/https://doi.org/10.5670/oceanog.2014.93.

Pinsky, M. L., Worm, B., Fogarty, M. J., Sarmiento, J. L., \& Levin, S. A. (2013). Marine taxa track local climate velocities. Science, 341(6151), 1239-1242.

https://doi.org/10.1126/science.1239352

Poloczanska, E. S., Brown, C. J., Sydeman, W. J., Kiessling, W., Schoeman, D. S., Moore, P. J., ... Richardson, A. J. (2013). Global imprint of climate change on marine life. Nature Climate Change, 3(10), 919-925. https://doi.org/10.1038/nclimate1958

Pörtner, H.-O., Karl, D.M., Boyd, P.W., Cheung W.W.L., Lluch-Cota, S.E., Nojiri, Y., Schmidt, D.N., and Zavialov, P.O. (2014). Ocean systems. In Field, C.B., V.R. Barros, D.J. Dokken, K.J. Mach, M.D., Mastrandrea, T.E. Bilir, M. Chatterjee, K.L. Ebi, Y.O. Estrada, R.C. Genova, B. Girma, E.S. Kissel, A.N. Levy, S. MacCracken, P.R. Mastrandrea, and L.L. White (eds.) Climate Change 2014: Impacts, Adaptation, and Vulnerability. Part A: Global and Sectoral Aspects. Contribution of Working Group II to the Fifth Assessment Report of the Intergovernmental Panel on Climate Change. Cambridge University Press, Cambridge, United Kingdom and New York, NY, USA, pp. 411-484.

Pörtner, H.-O. (2001). Climate change and temperature-dependent biogeography: Oxygen limitation of thermal tolerance in animals. Naturwissenschaften, 88(4), 137-146. https://doi.org/10.1007/s001140100216

Pörtner, H. -O., \& Knust, R. (2007). Climate change affects marine fishes trhough the oxygen 
limitation of thermal tolerance, 315(5808), 95-97.

https://doi.org/10.1126/science.1135471

R Core Team (2013). R: A language and environment for statistical computing. R Foundation for Statistical Computing, Vienna, Austria. URL http://www.R-project.org/.

Racault, M. F., Le Quéré, C., Buitenhuis, E., Sathyendranath, S., \& Platt, T. (2012).

Phytoplankton phenology in the global ocean. Ecological Indicators, 14(1), 152-163. https://doi.org/10.1016/j.ecolind.2011.07.010

Riahi, K., Rao, S., Krey, V., Cho, C., Chirkov, V., Fischer, G., ... Rafaj, P. (2011). RCP 8.5A scenario of comparatively high greenhouse gas emissions. Climatic Change, 109(1), 33-57. https://doi.org/10.1007/s10584-011-0149-y

Ruane, A. C., Teichmann, C., Arnell, N. W., Carter, T. R., Ebi, K. L., Frieler, K., ... Vincent, K. (2016). The Vulnerability, Impacts, Adaptation and Climate Services Advisory Board (VIACS AB v1.0) contribution to CMIP6. Geoscientific Model Development, 9(9), 3493-3515. https://doi.org/10.5194/gmd-9-3493-2016

Schellnhuber, H. J., Frieler, K., \& Kabat, P. (2013). The elephant, the blind, and the intersectoral intercomparison of climate impacts. Proceedings of the National Academy of Sciences of the United States of America, 111(9), 1-3. https://doi.org/10.1073/pnas.1321791111

Spence, M. A., Blanchard, J. L., Rossberg, A. G., Heath, M. R., Heymans, J. J., Mackinson, S., ... Blackwell, P. G. (2017). Multi-model ensembles for ecosystem prediction. ArXiv E-Prints, (September). arXiv preprint arXiv:1709.05189.

Stenson, G.B., Hammill, M. O. (2014). Can ice breeding seals adapt to habitat loss in a time of climate change. ICES Journal of Marine Science, 71(7), 1977-1986.

This article is protected by copyright. All rights reserved. 
https://doi.org/10.1093/icesjms/fsu074

Tittensor, D.P., Eddy, T.D., Lotze, H.K., Galbraith, E.D., Cheung, W, Barange, M., Blanchard, J.L., Bopp, L., Bryndum-Buchholz, A., Büchner, M., et al. 2018a. A protocol for the intercomparsion of marine fishery and ecosystem models: Fish-MIP v1.0. Geosci. Model Dev. 11, 1421-1442. http://doi.org/10.5194/gmd-11-1421-2018

Tittensor, D.P., Lotze, H.K., Eddy, T.D., Galbraith, E.D., Cheung, W.W.L., BryndumBuccholz,

A., Barange, M., Barrier, N., Bianchi, D., Blanchard, J.L., et al. 2018b. ISIMIP2a Simulation Data from Marine Ecosystems and Fisheries (Fish-MIP; global) Sector. GFZ Data Services. http://doi.org/10.5880/PIK.2018.005

van Vuuren, D. P., Edmonds, J., Kainuma, M., Riahi, K., Thomson, A., Hibbard, K., ... Rose, S. K. (2011). The representative concentration pathways: An overview. Climatic Change, 109(1), 5-31. https://doi.org/10.1007/s10584-011-0148-z

Vichi, M., Manzini, E., Fogli, P. G., Alessandri, A., Patara, L., Scoccimarro, E., ... \& Navarra, A. (2011). Global and regional ocean carbon uptake and climate change: sensitivity to a substantial mitigation scenario. Climate dynamics, 37(9-10), 1929-1947.

Yasuhara, M., \& Danovaro, R. (2016). Temperature impacts on deep-sea biodiversity. Biological Reviews, 91(2), 275-287. https://doi.org/10.1111/brv.12169

Worm, B., \& Lotze, H.K. (2016) Marine biodiversity and climate change. Chapter 13 in: Letcher, T. (ed) Climate and global change: Observed impacts on Planet Earth. $2^{\text {nd }}$ Edition, Elsevier: 195-212.

This article is protected by copyright. All rights reserved. 


\section{TABLES}

Table 2 Overview of ensemble projections of total marine animal biomass under climate change in different ocean basins. Shown are the ensemble mean \% change in total animal biomass in 2090s relative to 1990s based on ensemble projections $(n=10$ ecosystem modelEarth system model combinations), and three ensemble agreement metrics: one inter-model standard deviation of the ensemble mean, robustness index (Bopp et al. 2013), and model agreement $(\%)$ in the direction of change. Robustness index $>1$ indicates high robustness; Model agreement represents the agreement in the direction of change. RCP2.6 represents a strong climate change mitigation scenario, RCP8.5 a high emissions scenario.

\begin{tabular}{|c|c|c|c|c|}
\hline Ocean basin & $\begin{array}{l}\text { Ensemble } \\
\text { mean [\%] }\end{array}$ & $\begin{array}{l}\text { Inter-model } \\
\text { st.dev [\%] }\end{array}$ & $\begin{array}{c}\text { Robustness } \\
\text { index* }\end{array}$ & $\begin{array}{c}\text { Model } \\
\text { agreement }[\%]^{* *}\end{array}$ \\
\hline \multicolumn{5}{|l|}{ RCP 2.6} \\
\hline North Atlantic Ocean & -12.36 & 4.26 & 2.68 & 100 \\
\hline South Atlantic Ocean & -5.01 & 4.48 & 1.12 & 83 \\
\hline North Pacific Ocean & -8.53 & 5.76 & 1.48 & 100 \\
\hline South Pacific Ocean & -6.30 & 3.82 & 1.65 & 100 \\
\hline Indian Ocean & -4.69 & 4.26 & 1.10 & 83 \\
\hline Southern Ocean & -2.93 & 3.09 & 0.95 & 83 \\
\hline Arctic Ocean & 48.33 & 93.75 & 0.52 & 100 \\
\hline \multicolumn{5}{|l|}{ RCP 8.5} \\
\hline North Atlantic Ocean & -31.71 & 14.12 & 2.25 & 100 \\
\hline South Atlantic Ocean & -14.29 & 12.31 & 1.16 & 100 \\
\hline North Pacific Ocean & -25.54 & 16.89 & 1.51 & 100 \\
\hline South Pacific Ocean & -19.20 & 11.80 & 1.63 & 100 \\
\hline Indian Ocean & -20.38 & 13.96 & 1.46 & 100 \\
\hline Southern Ocean & 19.15 & 35.61 & 0.54 & 100 \\
\hline Arctic Ocean & 81.99 & 201.07 & 0.41 & 50 \\
\hline
\end{tabular}

This article is protected by copyright. All rights reserved. 


\section{FIGURE CAPTIONS}

Figure 1. Overview of ocean basin boundaries for this study (defined basin boundaries modified from IHO 1953). Note that the Mediterranean Sea, Black Sea and Baltic Sea were excluded from our analysis (grey cross-pattern on map).

Figure 2. Ensemble means of projected historical and future marine animal biomass and environmental drivers (Sea surface temperature: SST; Net primary production: NPP) across ocean basins under high climate change mitigation (Emissions scenario RCP2.6) for 19702100. Total animal biomass and NPP trends are in \% change and SST trends in degree ${ }^{\circ} \mathrm{C}$ relative to 1990-1999. Note different axis for each variable, and different axes scales in Arctic and Southern Ocean.

Figure 3. Ensemble means of projected historical and future marine animal biomass and environmental drivers (Sea surface temperature: SST; Net primary production: NPP) across ocean basins under low climate change mitigation and strong climate change (Emissions scenario RCP8.5) for 1970-2100. Total animal biomass and NPP trends are in \% change and SST trends in degree ${ }^{\circ} \mathrm{C}$ relative to $1990-1999$. Note different axis for each variable, and different axes scales in Arctic and Southern Ocean.

This article is protected by copyright. All rights reserved. 
Figure 4. Model projections for marine animal biomass of three size-classes across ocean basins under climate change for the high emissions scenario RCP8.5. Marine animal sizeclasses: Small marine animals $<10 \mathrm{~cm}$ ( $\mathrm{n}=6$ ecosystem-Earth system model combinations); medium-sized marine animals $10-30 \mathrm{~cm}(\mathrm{n}=8)$; large marine animals $>30 \mathrm{~cm}(\mathrm{n}=8)$. All changes are the mean of the 2090s relative to the 1990s. Boxplots: the upper and lower hinges correspond to the $1^{\text {st }}$ and $3^{\text {rd }}$ quartiles; the upper/lower whiskers extend to the highest/lowest value within 1.5 times the interquartile range; horizontal lines within boxes correspond to the median; diamonds represent the mean; outlier dots represent data beyond the end of the whiskers. For changes under RCP2.6 see Figure S6.

Figure 5. Climate change mitigation effect (RCP2.6 - RCP8.5) on ensemble projections of total marine animal biomass. Vertical line: target year for most UN Sustainable Development Goals. 

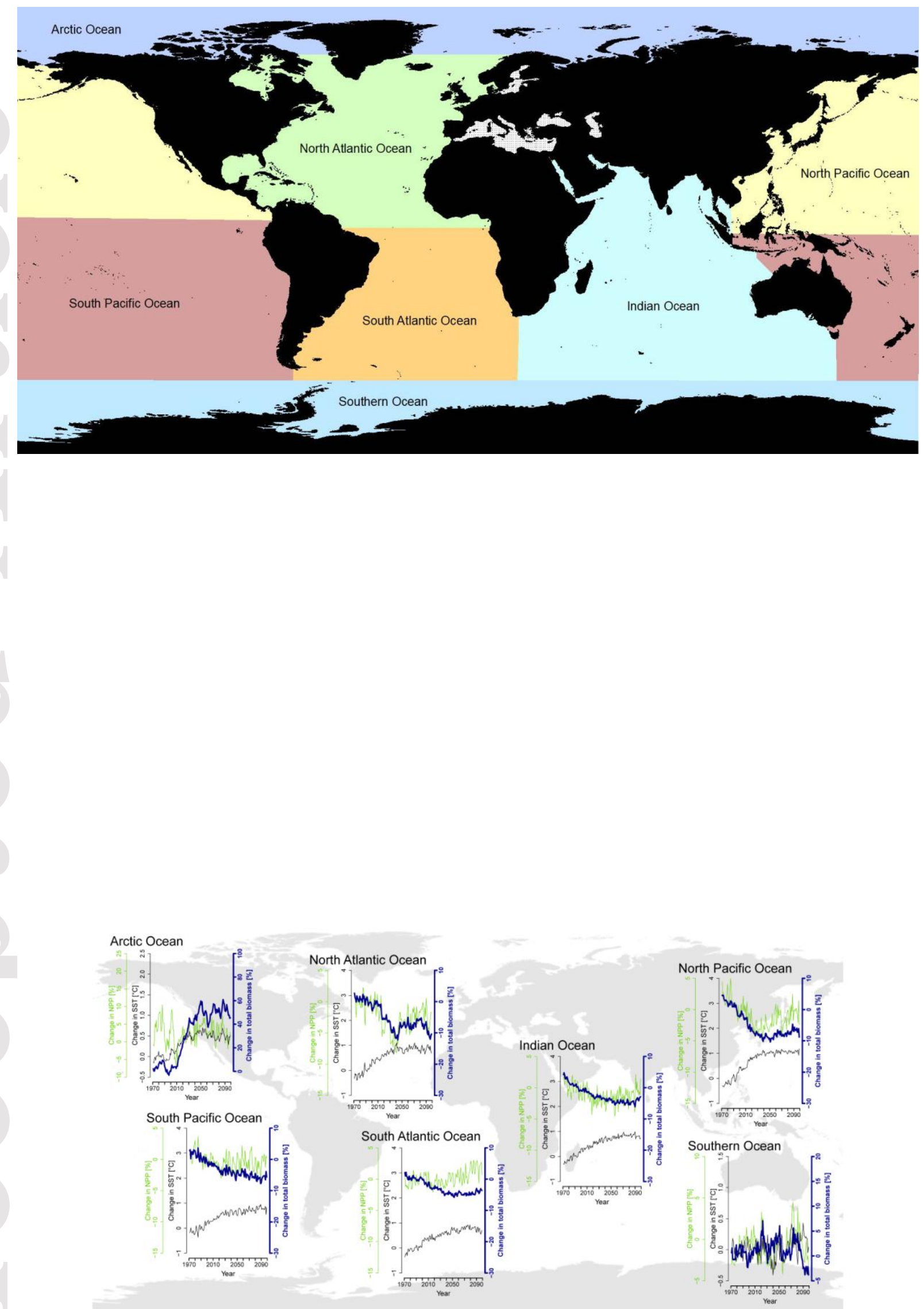

This article is protected by copyright. All rights reserved. 

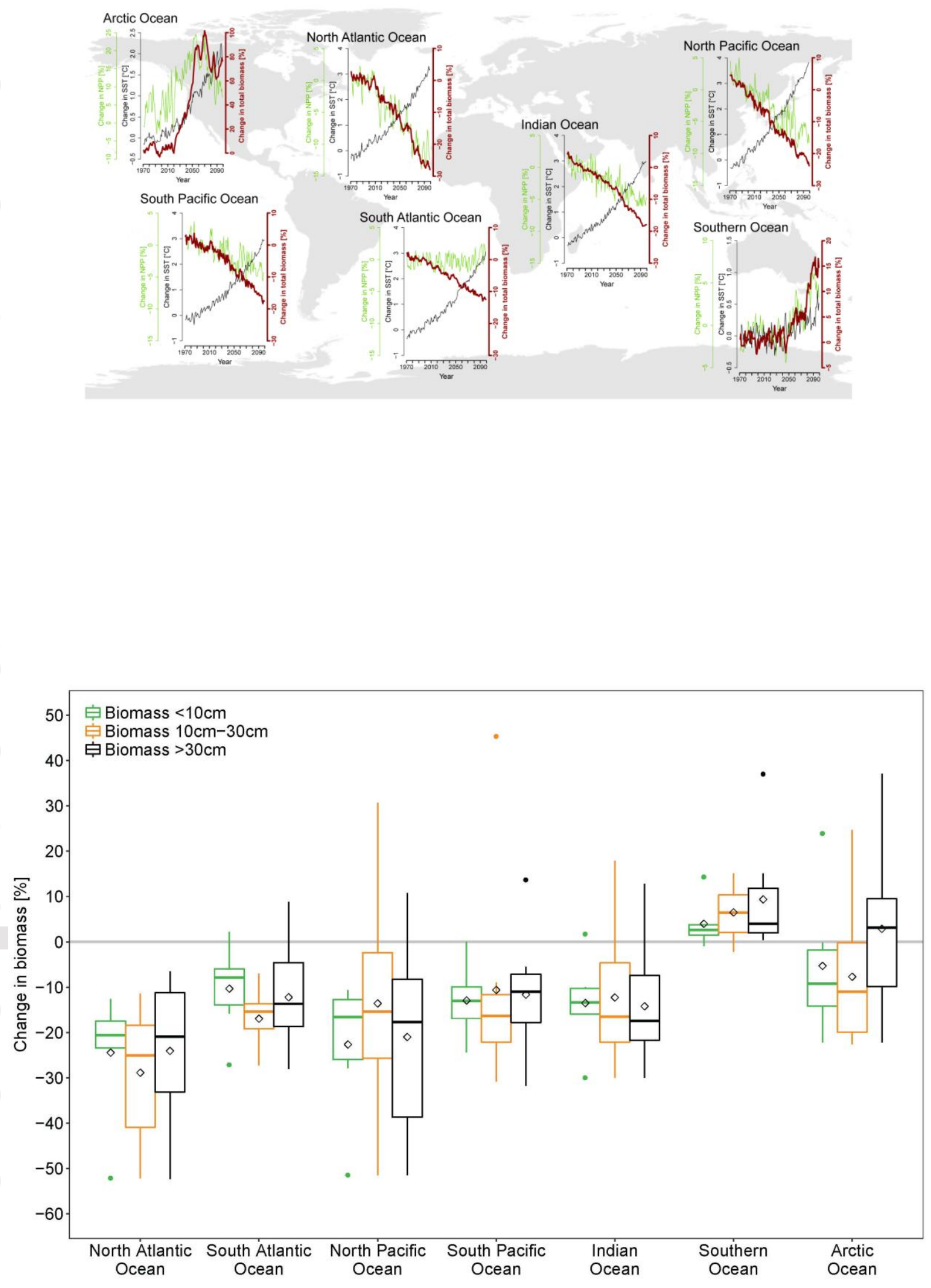

This article is protected by copyright. All rights reserved. 


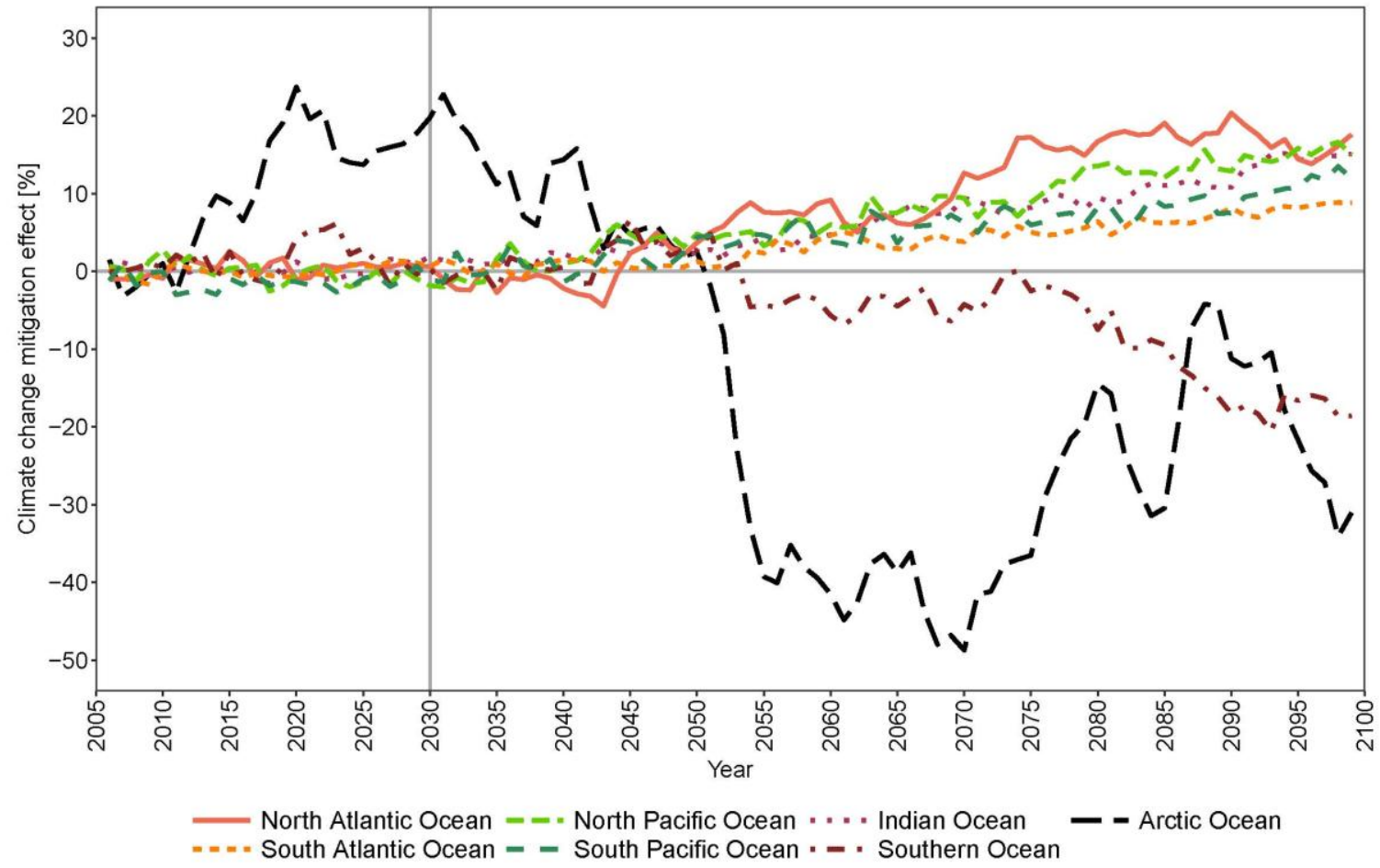

This article is protected by copyright. All rights reserved. 